Check for updates

Cite this: J. Anal. At. Spectrom., 2018, 33,1256

Received 28th November 2017 Accepted 18th May 2018

DOI: $10.1039 / c 7 j a 00395 a$

rsc.li/jaas

\section{Quantification of silver nanoparticles taken up by single cells using inductively coupled plasma mass spectrometry in the single cell measurement mode $\dagger$}

\author{
Ana López-Serrano Oliver, (D) *a Sabine Baumgart, ${ }^{b}$ Wolfram Bremser, ${ }^{a}$ \\ Sabine Flemig, ${ }^{a}$ Doreen Wittke, ${ }^{\mathrm{c}}$ Andreas Grützkau, (D) ${ }^{\mathrm{b}}$ Andreas Luch, (D) c \\ Andrea Haase (D) ${ }^{c}$ and Norbert Jakubowski (D) ${ }^{a}$
}

\begin{abstract}
The impact of nanoparticles, NPs, at the single cell level has become a major field of toxicological research and different analytical methodologies are being investigated to obtain biological and toxicological information to better understand the mechanisms of cell-NP interactions. Here, inductively coupled plasma mass spectrometry in the single cell measurement mode (SC-ICP-MS) is proposed to study the uptake of silver NPs, AgNPs, with a diameter of $50 \mathrm{~nm}$ by human THP-1 monocytes in a proof-ofprinciple experiment. The main operating parameters of SC-ICP-MS have been optimized and applied for subsequent quantitative analysis of AgNPs to determine the number of particles in individual cells using AgNP suspensions for calibration. THP-1 cells were incubated with AgNP suspensions with concentrations of 0.1 and $1 \mu \mathrm{g} \mathrm{mL}^{-1}$ for 4 and 24 hours. The results reveal that the AgNP uptake by THP-1 monocytes is minimal at the lower dose of $0.1 \mu \mathrm{g} \mathrm{mL}^{-1}$ (roughly $1 \mathrm{AgNP}$ per cell was determined), whereas a large cell-to-cell variance dependent on the exposure time is observed for a 10 times higher concentration (roughly 7 AgNPs per cell). The method was further applied to monitor the AgNP uptake by THP-1 cells differentiated macrophages incubated at the same AgNP concentration levels and exposure times demonstrating a much higher AgNP uptake (roughly from 9 to 45 AgNPs per cell) that was dependent on exposure concentration and remained constant over time. The results have been compared and validated by sample digestion followed by ICP-MS analysis as well as with other alternative promising techniques providing single cell analysis.
\end{abstract}

\section{Introduction}

The impact of nanoparticles, NPs, on cells is a key question in biomedical applications as well as in nanotoxicology and numerous analytical methods such as fluorescence and electron microscopy, mass spectrometry imaging, and mass and flow cytometric approaches have been applied to understand the extent and mode of cell-NP interactions. ${ }^{\mathbf{1 - 4}}$ However, such methodologies are still in their infancy to resolve cell-associated NP uptake and the analysis of NPs at the single cell level remains a challenge. Most traditional methods involve the bulk analysis of a large number of cells by lysis, extraction or

${ }^{a} B A M$ Federal Institute for Materials Research and Testing, Richard-Willstaetter Str. 11, 12489, Berlin, Germany. E-mail: anlopezs@ucm.es

${ }^{b}$ German Rheumatism Research Centre Berlin (DRFZ), Charitéplatz 1, 10117, Berlin, Germany

${ }^{c}$ Department of Product Safety, German Federal Institute for Risk and Assessment (BfR), Max-Dohrn-Str. 8-10, 10589 Berlin, Germany

$\dagger$ Electronic supplementary information (ESI) available. See DOI: 10.1039/c7ja00395a digestion, only providing average data from thousands of cells and masking the stochastic diversity of individual cellular responses. ${ }^{5,6}$ The mechanisms of cell-NP interactions are not well understood yet and the development and validation of new reliable methods that enable the analysis and identification of NPs at the single cell level providing information on the number of NPs internalized by cells or externally bound to the cell surface are urgently required.

Single cell analysis using time-resolved ICP-MS, SC-ICP-MS, is receiving considerable attention because of its important analytical advantages such as the minimal sample preparation required and its ability to provide information about the cell variance within a cell population. Briefly, cell suspensions are sprayed by conventional pneumatic nebulization into the high temperature plasma where each cell is desolvated, vaporized, and dissociated and its constituents are atomized and ionized. The resulting ion cloud from each single cell is detected by mass spectrometry generating a spike signal with an intensity proportional to the quantity of the analyte atoms in a single cell, and the number of spike signals is proportional to the number 
of cells in solution if the nebulizer efficiency is known. SC-ICPMS has already been applied in single cell analysis to determine major intracellular elements such as calcium and magnesium in unicellular algae, Chlorella vulgaris. ${ }^{7}$ Other authors have recently reported the quantitative analysis of silver NPs, AgNPs, and titanium dioxide $\mathrm{NPs}, \mathrm{TiO}_{2} \mathrm{NPs}$, in lysated neuro-2a cells after incubation at different doses of NPs by SC-ICP-MS. ${ }^{8}$ However, SC-ICP-MS has not yet been applied to assess the AgNP uptake of intact living cells and their distribution among the single cell population.

The aim of this proof-of-principle experiment is the development of a detection and calibration scheme for SC-ICP-MS to monitor the uptake of AgNPs by intact individual cells. The main analytical characteristics of SC-ICP-MS such as the integration time and cell concentration were optimized and validated for the quantitative analysis of AgNPs $(50 \mathrm{~nm})$ in human THP-1 monocytes (as non-adherent cells). THP-1 monocytes were chosen here to evaluate the feasibility of SC-ICP-MS since a much lower number of AgNPs taken up per single cell was expected. The developed SC-ICP-MS method was further applied to monitor the AgNP uptake by partially differentiated THP-1 macrophages (as non-adherent cells as well), a cell line with high toxicological interest commonly used in "in vitro" studies. ${ }^{9}$ THP-1 cells were exposed to two different AgNP concentration levels, 0.1 and $1 \mu \mathrm{g} \mathrm{mL}^{-1}$, for 4 and $24 \mathrm{~h}$. Then, the quantitative analysis of AgNPs in THP-1 cells was accomplished by measuring AgNPs in aqueous and single cell suspensions, which is feasible if AgNPs in different matrices have the same ionization behavior in the plasma. The results obtained by SC-ICP-MS were compared and validated by parallel measurements with ICP-MS after digestion of the cell suspension as well as with other alternative promising techniques, providing single cell analysis such as mass cytometry, СyTOF, and the profiling method step FIB/SEM slice and view. ${ }^{\mathbf{1 0}}$

\section{Experimental}

\section{Chemicals}

Monodisperse, citrate buffered AgNPs with a diameter of $47 \pm$ $5 \mathrm{~nm}$ and a particle concentration of $1.9 \times 10^{12}$ particles $\mathrm{mL}^{-1}$ were purchased from nanoComposix (San Diego, CA, USA). A silver standard solution of dissolved $\mathrm{AgNO}_{3}$, indium standard solution, ICP-MS multi-element standard solution containing $\mathrm{Li}$, In and $\mathrm{U}\left(10 \mathrm{mg} \mathrm{L}^{-1}\right)$ in $2 \%$ nitric acid, $65 \% \mathrm{w} / \mathrm{w}$ ultrapure grade nitric acid and hydrogen peroxide were purchased from Merck (Darmstadt, Germany). Phosphate Buffered Saline (PBS) was obtained from Beyotime Institute of Biotechnology (Beijing, China). Roswell Park Memorial Institute (RPMI) medium and ultra-pure sterile water were obtained from Biochrom (Berlin, Germany). Phorbol-12-myristate-13-acetate (PMA) was purchased from Merck and Sigma Aldrich (St. Louis, MO, USA). Fetal calf serum (FCS), 4-(2-hydroxyethyl)-1piperazineethanesulfonic acid (HEPES), pyruvate, penicillin, streptomycin and L-glutamine were provided by Pan Biotech GmbH (Aidenbach, Germany). Roti® Histofix 4\% (phosphatebuffered formaldehyde solution 4\% (PFA) stabilized with acidfree methanol ( $\mathrm{pH} \mathrm{7)}$ ) for cell fixation was obtained from Carl
Roth (Karlsruhe, Germany). Milli-Q water from purification system Millipore Gradient, Merck Millipore, Darmstadt, Germany was used for dilution of standards.

\section{THP-1 cell culture conditions and treatments}

The THP-1 cell line was obtained from the German Collection of Microorganisms and Cell Cultures GmbH (DSMZ, Braunschweig, Germany). To get THP-1 monocytes, cells were grown at $37{ }^{\circ} \mathrm{C}$ with $5 \% \mathrm{CO}_{2}$ in RPMI medium supplemented with $10 \%$ FCS, $2 \mathrm{mM}$ L-glutamine, $10 \mathrm{mM}$ HEPES, $1 \mathrm{mM}$ pyruvate, $100 \mathrm{U}$ $\mathrm{mL}^{-1}$ penicillin and $100 \mu \mathrm{g} \mathrm{mL}^{-1}$ streptomycin. Moreover, for differentiation the THP-1 monocytes were stimulated with 100 $\mathrm{ng} \mathrm{mL} \mathrm{L}^{-1}$ PMA dissolved in Milli-Q water for $48 \mathrm{~h}$ at $37^{\circ} \mathrm{C}$ in $5 \%$ $\mathrm{CO}_{2}$ in air to get THP-1 cells partially differentiated into macrophages (macrophage-like cells), which are still suspension cells whereas fully differentiated macrophages are adherent cells.

The AgNP suspension at a concentration of $1.06 \mathrm{mg} \mathrm{mL}^{-1}$ was sonicated for five minutes to avoid AgNP aggregation and added to the RPMI media to achieve final AgNP concentrations of 0.1 and $1 \mu \mathrm{g} \mathrm{mL}{ }^{-1}$. After incubation with AgNPs for 4 and 24 hours, THP-1 cell suspensions were washed three times with PBS buffer to remove free-floating AgNPs in the incubation media or loosely attached to the cell surface. After centrifugation, the collected cell pellets were fixed with 4\% PFA, washed again with PBS, re-suspended in ultrapure sterile water and diluted to a cell number density of $10^{4}$ to $10^{5}$ cells $\mathrm{mL}^{-1}$, having been accurately counted in advance by using a counting chamber, C-Chip (Biochrom, Germany), and a binocular microscope, VisiScope BL 124 from VWR (Darmstadt, Germany). Then the silver ion signal intensity at the single cell level was measured by SC-ICP-MS immediately after re-suspension.

\section{ICP-MS measurements}

The silver intensity of the AgNPs in aqueous or single cell suspensions and digested cells was measured using an ICP-MS Sector Field instrument (Element XR/2, Thermo Fisher Scientific GmbH, Bremen Germany) in a time resolved analysis (TRA) mode with a data acquisition rate, or dwell time, of $0.1 \mathrm{~ms}$ during $52 \mathrm{~s}$ per measurement. For data acquisition at such a low dwell time a fast scanning mode (E-scan) was used to measure single cell/particle events as described before by Shigeta et al. ${ }^{\mathbf{1 1}}$ with the exception of the "mass window" that was fit to $10 \%$ in this study. At the end of each mass window, the magnet switches back to the start position, and thus a settling time of 3$4 \mathrm{~ms}$ previously estimated for the ICP-MS sector field was used throughout the experiments. ${ }^{12}$ This settling time could not be predicted for AgNPs associated with cells and its influence was corrected assuming the same behaviour for samples and AgNP standards used for calibration. However, the dead time was not determined for this instrument and might account for an additional source of error since the detector saturates once a value of $4 \times 10^{6}$ counts per second (cps) is reached in a single integration channel (it switches off and remains off for the next signals as long as the intensity remains below this value). A concentric nebulizer (Micromist $0.2 \mathrm{~mL}$, L90350, AHF 
Analysentechnik) and a conical quartz spray chamber with an impact bead were used to generate an aerosol in which each individual cell is surrounded by a liquid layer of solvent as small droplets which are finally transferred to the detector with a reduced transport efficiency as described below.

The typical operating parameters of ICP-MS are summarized in Table S1 (ESI). $\dagger$ Before each experiment, the ICP-MS instrument was tuned using an aqueous multi-element standard solution $\left(1 \mathrm{ng} \mathrm{mL} \mathrm{m}^{-1}\right.$ each of $\mathrm{Li}$, In and $\mathrm{U}$ stabilized in $2 \%$ nitric acid for ICP-MS) for consistent sensitivity.

For quantitative analysis of AgNPs in aqueous or cell suspensions different AgNP suspensions with $\mathrm{Ag}$ concentrations of $0.025,0.05$ and $0.1 \mathrm{ng} \mathrm{mL}{ }^{-1}$ were used for calibration purposes. The detector voltage was optimized to achieve a lower sensitivity for $\mathrm{Ag}$ detection and to avoid detector saturation for those cells containing a high number of AgNPs at the highest concentration and longest incubation time. For this purpose, different concentrations of AgNP ( $50 \mathrm{~nm}$ ) aqueous suspensions were prepared and measured to optimize the detector voltage which was decreased from 1900 to $1580-1650 \mathrm{~V}$ in order to obtain a minimal $\mathrm{Ag}$ intensity signal for a single AgNP and maintain an acceptable signal intensity (at about $1 \times 10^{5}$ counts per second, cps) and dynamic range. Then, under these optimal low sensitivity conditions found for the $x-y$-position of the torch, rf power, gas flow rates and dwell time, as well as optimal cell concentration, the ${ }^{107} \mathrm{Ag}$ ion signal intensity of AgNPs in samples as AgNP aqueous or single cell suspensions was measured by SC-ICP-MS as a function of time (cps). Due to the short dwell time employed in single cell mode, it was not possible to switch between different $\mathrm{m} / \mathrm{z}$ values and therefore only one of the naturally abundant isotopes for $\mathrm{Ag}$ was monitored during each measurement cycle. The ${ }^{107} \mathrm{Ag}$ isotope was selected for further analysis as both isotopes, ${ }^{107} \mathrm{Ag}$ and ${ }^{109} \mathrm{Ag}$, provided similar Ag intensity signals due to their natural abundance. However, the use of the ${ }^{115}$ In ion signal intensity as the internal standard was also tested and alternatively measured to correct variations in the instrument sensitivity for the quantitative analysis of AgNPs at the single cell level. The data of all these experiments were recorded using Thermo Plasma Lab software and transferred into Origin $\mathbf{1 5 . 0}$ format for data analysis.

To compare and validate the SC-ICP-MS results, the mean concentration of AgNPs in THP-1 cells was determined by bulk analysis ICP-MS after cell digestion. Briefly, after cell exposure an aliquot containing roughly $10^{5}$ cells $\mathrm{mL}^{-1}$ (being accurately counted by using a counting chamber, C-Chip) was washed three times with PBS, centrifuged to remove the supernatant and the cell pellet remaining was digested overnight at room temperature by adding $0.15 \mathrm{~mL}$ of concentrated nitric acid. The next day, $0.05 \mathrm{~mL}$ of hydrogen peroxide was added to the digested solution and the mixture diluted properly with Milli Q water. Then, the instrumental parameters were readjusted and optimized to achieve the highest sensitivity for $\mathrm{Ag}$ detection when measuring digested cell samples and silver standard solutions (the detector voltage was again increased to $1900 \mathrm{~V}$ ). Different concentrations of silver standards $\left(0.5,1,5\right.$ and $\left.10 \mathrm{ng} \mathrm{Ag} \mathrm{mL}{ }^{-1}\right)$ were used to quantify the absolute mass of $\mathrm{Ag}$ in the digested samples. To correct the instrumental variations in sensitivity during the analysis, indium was added to the digested samples as an internal standard at a final concentration of $1 \mathrm{ng} \mathrm{mL}^{-1}$. Subsequently, the total number of AgNPs taken up by each single cell was calculated using the number of cells counted before digestion.

\section{Results and discussion}

\section{Optimization of cell concentration and dwell time for SC-ICP- MS}

For single cell ICP-MS analysis, it is a prerequisite that only one cell should enter the plasma at a given integration time interval so that each spike signal of the selected isotope (here ${ }^{107} \mathrm{Ag}$ ) corresponds to a single cell event. According to this principle of SC-ICP-MS, the two main parameters that may have a strong influence on the measurement of a single cell event, i.e. dwell time and cell concentration, were optimized.

Considering that short dwell times are being used in SC-ICPMS to decrease the background noise level but do not affect the spike intensity signal, three different dwell time values of 10, 1 and $0.1 \mathrm{~ms}$ were tested here. In Table 1 the number of events detected for the analysis of AgNPs in aqueous and single cell suspensions at each dwell time evaluated is compiled. The data show an increase of about $30 \%$ in the number of particle/cell events when measuring AgNP aqueous or single cell suspensions at the lowest dwell time of $0.1 \mathrm{~ms}$ in comparison to the highest dwell time of $10 \mathrm{~ms}$. The reason is that counting of cell duplicates is more pronounced for integration times longer than the ion cloud duration from a single cell or particle event of 300-500 $\mu \mathrm{s}^{11}$ However, for shorter dwell time values, for instance $0.1 \mathrm{~ms}$, a single cell event is distributed over 3 to 5 spike intensity signals corresponding to partial sections of the ion cloud that need to be combined to reconstruct the cell/ particle pulse and obtain mass and particle number data. Here, the entire signal from a single cell event was integrated over three to six data points when using a dwell time of $0.1 \mathrm{~ms}$ as described before. ${ }^{11}$ Moreover, a dwell time of $0.1 \mathrm{~ms}$ correlates with faster acquisition and more cells can be introduced without increasing the probability of coincidence events. Therefore, a dwell time of $0.1 \mathrm{~ms}$ was chosen here to improve the signal-to-noise ratio, the counting statistics and the particle mass and concentration calculations.

Table 1 Effect of the dwell time on the number of events detected as AgNP transient signals during 52 seconds of acquisition. SC-ICP-MS measurements of $0.050 \mathrm{ng} \mathrm{mL}^{-1}$ AgNPs in aqueous and single cell suspensions (corresponding to $1 \times 10^{5}$ cells $\mathrm{mL}^{-1}$ THP-1 monocytes incubated at a concentration of $1 \mu \mathrm{g} \mathrm{mL}^{-1}$ AgNPs for 4 hours). All intensities measured 3 times above the background were considered and counted as AgNP or/and single cell events without background data correction

\begin{tabular}{lll}
\hline $\begin{array}{l}\text { Dwell time, } \\
\mathrm{ms}\end{array}$ & $\begin{array}{l}\text { AgNP events in aqueous } \\
\text { suspensions }\end{array}$ & $\begin{array}{l}\text { AgNP events in } \\
\text { cell suspensions }\end{array}$ \\
\hline 0.1 & 306 & 451 \\
1 & 260 & 393 \\
10 & 210 & 220
\end{tabular}


The cell concentration needs to be optimized as well to obtain sensitive and accurate signals of single cells by SC-ICPMS. Here, a cell concentration range between $5 \times 10^{4}$ and $3 \times$ $10^{5}$ cells $\mathrm{mL}^{-1}$ was tested for SC-ICP-MS analysis by using a fixed dwell time of $0.1 \mathrm{~ms}$. Fig. S1 (ESI) $\uparrow$ shows the effect of the cell concentration on the signal profile of THP-1 monocytic single cells. The number of cell events detected increased with cell concentration from $5 \times 10^{4}$ to $1 \times 10^{5}$ cells $\mathrm{mL}^{-1}$, whereas they decreased for concentrations above $1 \times 10^{5}$ cells $\mathrm{mL}^{-1}$ due to multiple cell ionization events during the same counting interval that increased the background signal as well. Therefore, a maximal cell concentration of $1 \times 10^{5}$ cells $\mathrm{mL}^{-1}$ was chosen for further experiments.

\section{Determination of transport efficiency of the pneumatic nebulizer}

For SC-ICP-MS the transport efficiency, $\varepsilon$, is also an essential parameter needed for determining the number of cells reaching the detector in the analyzed sample. In this study, $\varepsilon$ was determined for AgNPs by measuring suspensions of AgNP standards with known particle concentrations according to Kanaki et al. ${ }^{13}$ Three different AgNP suspensions were prepared at concentra-

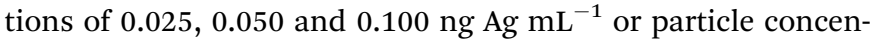
tration of $3.64 \times 10^{4}, 7.29 \times 10^{4}$ and $1.46 \times 10^{5} \mathrm{AgNPs} \mathrm{mL}^{-1}$, respectively, and $\varepsilon$ was calculated using the following equation:

$$
\varepsilon=\frac{N}{Q_{\mathrm{sp}} N_{\mathrm{AgNPs}} t}
$$

where $Q_{\mathrm{sp}}$ is the sample uptake rate $\left(\mathrm{mL} \mathrm{s}^{-1}\right), N_{\mathrm{AgNPs}}$ is the AgNP concentration (number of AgNPs $\mathrm{mL}^{-1}$ ), $t$ is the acquisition time (s), and $N$ is the number of events/signals detected per second. In Table S2 (ESI) $\dagger$ the experimental $\varepsilon$ values obtained are listed when using the particle concentrations described above $\left(N_{\text {AgNPs }}\right)$, a sample uptake rate of $0.004 \mathrm{~mL} \mathrm{~s}^{-1}$, an acquisition time of $52 \mathrm{~s}$, and the number of cell events detected per second. An average transport efficiency value of $2 \%$ was estimated for $50 \mathrm{~nm}$ AgNPs (Table S2, ESI $\dagger$ ), which is comparable to the typical transport efficiency for NPs provided in the literature. ${ }^{13}$

For cells, the transport efficiency was estimated by measuring the cell samples treated with AgNPs at the highest exposure time assuming that each cell contains at least one single AgNP. Considering the number of detected cell events per time resolved ICP-MS profile (roughly 500-700), the same parameters described for AgNP suspensions and a maximal cell concentration of $1 \times 10^{5}$ cells $\mathrm{mL}^{-1}$, a similar transport efficiency value between 2 and $3 \%$ was estimated demonstrating that the size of the droplets generated by the nebulizer and not the size of cells is the limiting factor. This value obtained here is comparable to other previous studies reporting cell introduction efficiencies of $<3 \%$ by using the same spray chamber ${ }^{14}$ but might be improved by application of high efficiency sample introduction systems in future.

\section{External calibration strategy}

For quantitative analysis of the number of AgNPs taken up by THP-1 cells, AgNP concentrations of 0.025, 0.050 and $0.100 \mathrm{ng}$ Ag
$\mathrm{mL}^{-1}$ or particle concentrations of $3.64 \times 10^{4}, 7.29 \times 10^{4}$ and $1.46 \times 10^{5} \mathrm{AgNPs} \mathrm{mL}^{-1}$, respectively, were measured by SC-ICPMS under optimized low sensitivity conditions for calibration purposes. The plots in Fig. 1 display the number of particle events or the mean intensity value of ${ }^{107} \mathrm{Ag}$ versus the AgNP concentrations. As illustrated, increased AgNP concentrations lead only to an elevated number of particle events detected (Fig. 1 left) while the mean value of the ${ }^{107} \mathrm{Ag}$ intensity remains constant at about $1 \times 10^{5} \mathrm{cps}$ (Fig. 1 right) for each particle if multiple events in an integration window do not occur. The reason is that the number of atoms per particle is constant and only the number of particle events counted changes by varying the AgNP concentration. At too high AgNP concentrations, multiple events might be expected and thus higher concentrations should be avoided for the NP suspensions as well. Therefore, to calculate the number of AgNPs per individual cell, the measured ${ }^{107} \mathrm{Ag}$ signal intensity of each spike signal from a single cell was divided by the mean ${ }^{107} \mathrm{Ag}$ intensity for one single AgNP. By using this quantification approach, the minimum $\mathrm{Ag}$ amount detectable or limit of detection, LOD, corresponds to just one single AgNP, assuming AgNPs are not dissolved during the incubation and sample preparation. In terms of sensitivity, the ${ }^{107} \mathrm{Ag}$ signal intensity from one single AgNP was much higher compared with the statistically distributed background noise level. Therefore, the LOD can be correlated with the absolute mass of silver, $m$, by assuming that AgNPs are spheres (according to the manufacturer's product description) with a diameter, $d$, and the density of $\mathrm{Ag}, \rho\left(10.5 \mathrm{~g} \mathrm{~mL}^{-1}\right): m=\frac{4}{3} \pi[d / 2]^{3} \rho$; which results in $0.686 \mathrm{fg}$ of Ag per single AgNP.

Additionally, in SC-ICP-MS the continuous background response is a measure of dissolved silver, which was irrelevant for the AgNP aqueous suspensions used in this study. The particle concentration and the dissolved ionic silver rate from the AgNP aqueous suspension used as the standard was monitored after a week to evaluate their stability over time, with no chemical transformation, aggregation or dissolution being observed, which demonstrates that the AgNP standard was stable. This fact along with the low LOD achieved made calibration by using AgNPs a more accurate strategy for absolute quantification of NPs per single cell than the typical semi-quantitative approach based on continuous introduction of standard solutions of the corresponding ionic form, ${ }^{\mathbf{1 4}}$ which might cause errors in the final quantitative results because of a different chemical behaviour and ionization efficiency for particles and their corresponding dissolved ionic species. Therefore, we have exclusively used AgNP suspensions for calibration purposes throughout this investigation.

\section{Variation of AgNP concentration and incubation time in cell assay}

The AgNP concentration in the exposure/incubation media was controlled by SC-ICP-MS using the same AgNP aqueous suspensions previously employed for THP-1 cell exposure for quantification. Fig. S2 (ESI) $\dagger$ illustrates the AgNP nominal 

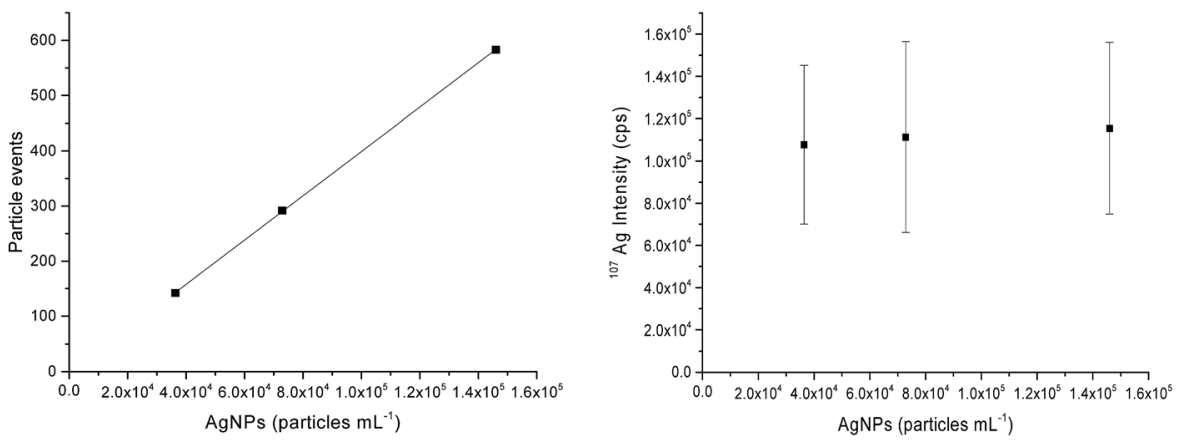

Fig. 1 External calibration with AgNPs. (Left) Measured number of AgNP events versus AgNP concentrations (equation: number of AgNP events $=0.0040 \times\left[\mathrm{AgNPs} \mathrm{mL} \mathrm{m}^{-1}\right]-2.90 ; R^{2}=0.999$ ). (Right) Measured ${ }^{107} \mathrm{Ag}$ in counts per second (cps) versus AgNP concentrations.

concentration in terms of $\mathrm{Ag}$ absolute mass at 0.1 and $1 \mu \mathrm{g}$ $\mathrm{mL}^{-1}$ for 0,4 and 24 hours of exposure. As can be seen in Fig. S2, $\uparrow$ the AgNP nominal concentration was highly stable without significant AgNP sedimentation, aggregation or silver dissolution for all concentrations and incubation times. Moreover, it shows that the uptake rate of AgNPs by THP- 1 cells is rather low, and so the concentration in the supernatant does not change significantly.

As discussed above, the quantitative analysis of the number of AgNPs taken up at the single cell level was performed by parallel measurements of AgNPs and cell suspensions by time resolved SC-ICP-MS under same optimized conditions. Indium was added to the samples as an internal standard to correct for instrumental changes during acquisition. However, the alternating instrumental switch between the two analyzed isotopes, ${ }^{107} \mathrm{Ag}$ and ${ }^{115} \mathrm{In}$, required a few ms per cycle settling time for the magnet and caused a strong decrease in the detected number of AgNPs in cell or aqueous suspensions. Since no drift was observed during the measurement time the idea to use indium as an internal standard for AgNP quantification at the single cell level was discarded.

Fig. 2a-d show the time resolved ICP-MS profiles obtained for THP-1 monocytes incubated with AgNPs at 0.1 and $1 \mu \mathrm{g} \mathrm{Ag}$ $\mathrm{mL}^{-1}$ for 4 and 24 hours. No visible Ag signals were detected in the control samples demonstrating that spectral interferences were not limiting and memory effects of AgNPs did not occur. In contrast, many ${ }^{107} \mathrm{Ag}$ spike signals above the noise level were observed in single cell suspensions exposed to AgNPs. Because cells had been washed several times before acquisition, the spike signals in the mass spectra can be fully attributed to AgNPs associated with cells. It should be mentioned that SCICP-MS cannot differentiate between internalized AgNPs and AgNPs externally bound to the cell surface. For validation of the NP internalization, step FIB/SEM slice and view was used in previous studies. ${ }^{10}$

Fig. $2 \mathrm{e}-\mathrm{h}$ show the corresponding histograms in terms of the number of AgNPs taken up per individual cells versus number of cell events at different AgNP exposure concentrations and incubation times. Here, signals three times above the mean value of the background intensity signal were considered as single cell events. As illustrated in Fig. 2, the uptake of AgNPs by THP-1 monocytes incubated at the lowest dose of $0.1 \mu \mathrm{g} \mathrm{mL}$ was minimal and close to the LOD even for the longest incubation time tested. Moreover, after 24 hours of exposure the fraction of cells containing AgNPs increased although the number of AgNPs associated with cells remained constant. Nevertheless, the AgNP uptake for THP-1 monocytes treated with the highest $\mathrm{AgNP}$ exposure dose $\left(1 \mu \mathrm{g} \mathrm{mL}{ }^{-1}\right)$ was dependent on incubation time. The histograms in Fig. 2e-h show an appearing right-hand tail, indicating that some individual cells contained multiple AgNPs, most likely aggregates as it was stated previously by Guehrs et al. in $2017 .{ }^{10}$ This right-hand tail was more pronounced for THP-1 monocytes treated at the highest exposure dose and time $\left(1 \mu \mathrm{g} \mathrm{mL} \mathrm{m}^{-1}, 24 \mathrm{~h}\right)$ (Fig. 2h).

As can be seen from the histograms displayed in Fig. $2 \mathrm{e}-\mathrm{h}$, the distribution of events per cell is leptokurtic and heavily righttailed. None of the commonly used distributions satisfactorily describe the effect of AgNP intrusion. Commonly used distributions, namely the normal, log-normal, exponential, gamma, and the Lorentz distribution were fitted to the experimental data, as well as a Kernel smoothing was applied. An example is given for THP-1 monocytes incubated at $1 \mu \mathrm{g} \mathrm{mL}{ }^{-1}$ AgNPs for an exposure time of $4 \mathrm{~h}$ in Fig. S3. $\dagger$ The experimental distribution is much steeper than any of the ones tested, has a clear zero region and a long but not significantly expressed right tail. A sensible description of such distributions might be done empirically (which can be challenged). However, here the mode of the distribution and an inter-quantile was used. Despite the common $50 \%$ inter-quartile, here a $67 \%$ inter-quantile was selected for both THP-1 cell types (monocytes and partially differentiated macrophages) in order to mimic the one-sigma of a normal distribution. It is clear that the lower and upper bounds of the quantile are heavily asymmetric, and thus an uncertainty $u_{-}$and an uncertainty $u_{+}$are indicated in Table S3. $\dagger$

Given the zero zones, not all distributions obtained for all experiments developed with both THP-1 cell types provide (f, from the mode, a half-of-the-quantile towards the lower edge) additional evidence of the heavily long-tailed distribution. In those cases, the $67 \%$ inter-quantile was assessed from the leftside foot edge towards the higher values, leading to even more asymmetric uncertainty estimates.

Fig. 2e-h display the data distributions in a coarse binning mode oriented at a $\sqrt[3]{N}$ rule. For determining the real mode of the distributions, a finely tuned binning with a span of normally 

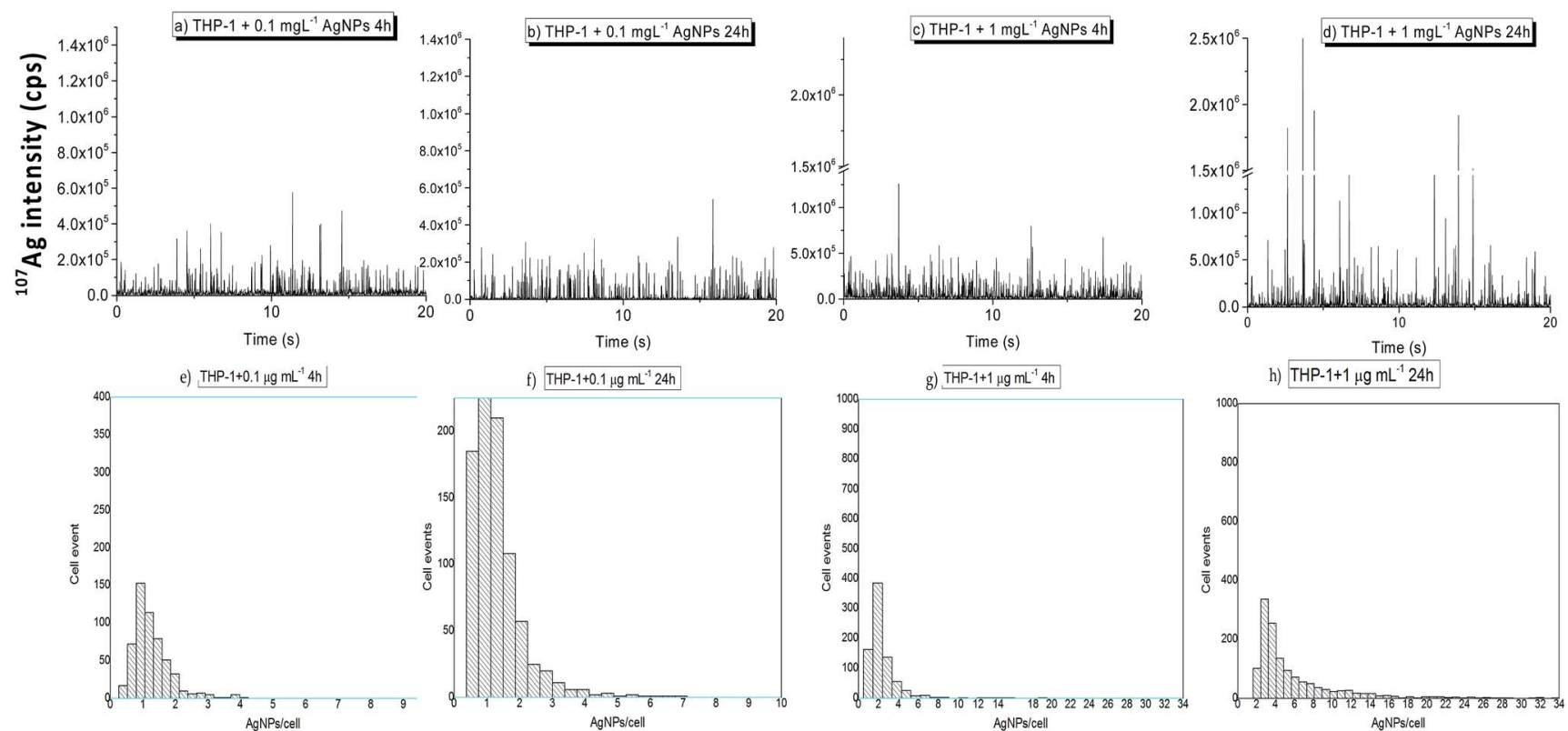

Fig. 2 SC-ICP-MS of single cell suspensions at a concentration of $5 \times 10^{4}$ to $1 \times 10^{5}$ cells $\mathrm{mL}^{-1}$. (a-d) Time resolved ICP-MS profiles and (e-h) histograms obtained for THP-1 monocytes incubated with $50 \mathrm{~nm}$ AgNPs at 0.1 and $1 \mu \mathrm{g} \mathrm{mL}^{-1}$ for 4 and 24 hours. The results correspond to two biological experiments measured in two replicates.

0.2 was used. This refers to the range of the $\mathrm{Ag}$ mass contained in one $\mathrm{NP}(47 \mathrm{~nm} \pm 5 \mathrm{~nm})$ resulting in a $20 \%(0.2)$ up-and-down variation of the measured signal per AgNP.

Five out of the eight experimental datasets (four for THP-1 monocytes and four for THP-1 partially differentiated macrophages after incubation with 0.1 and $1 \mu \mathrm{gL} \mathrm{m}^{-1} \mathrm{AgNPs}$ for an exposure time of 4 and 24 hours respectively) displayed clear modes with corresponding lower and upper uncertainties. The rest, in particular those corresponding to both THP-1 cell types exposed to $1 \mu \mathrm{g} \mathrm{mL} \mathrm{m}^{-1}$ AgNPs for an exposure time of $24 \mathrm{~h}$, revealed nearly equal contingency values over a (still narrow) range of contents. These spots out of the full distribution have been treated like rectangular distributions, and a mean was formed over that (little) range that probably best reflects the mode of the distribution.

The mode and uncertainties of the measured values have been converted to real cell events, taking into account the $\mathrm{Ag}$ content within the uncertainties of a single AgNP. The results obtained for the quantitative analysis of the number of AgNPs taken up by THP-1 monocytes and partially differentiated macrophages are summarized in Table S3. $\dagger$ From the results, some conclusions may be drawn, namely:

- Penetration time is significant. $24 \mathrm{~h}$ give throughout larger rates than $4 \mathrm{~h}$.

- Concentration of the AgNPs is less significant; an order of magnitude does not correspond to an order of magnitude in uptake.

- A full resistance to intrusion of AgNPs cannot be confirmed. There is at least one single or larger NP up-taking into a cell.

- An overwhelming majority of cells takes up small numbers of AgNPs. Some cells "suck in" AgNPs, the reason for the long-tailed distributions. Such tailing behaviour has been demonstrated in a previous study where the uptake of inorganic As at the single cell level was investigated, ${ }^{15}$ and so this tailing is not characteristic for NPs but for cells in general. In both studies the cell system was not synchronized, which means that cells are in different activity cycles once the experiment is started and thus have different uptake rates and even different uptake times which might deviate from the incubation time significantly. ${ }^{16}$

- The AgNP uptake by both THP-1 cell types (monocytes and partially differentiated macrophages) is comparable at least within the uncertainty ranges. Even so, the AgNP uptake is increased for THP-1 partially differentiated macrophage cells (Fig. S4†).

\section{Quantitative analysis of AgNPs by digestion ICP-MS}

For validation of the quantitative results obtained by SC-ICPMS the total number of AgNPs taken up at the single cell level was calculated by bulk analysis of roughly one thousand digested cells by ICP-MS as described in the Experimental section. The absolute mass of Ag was determined by interpolating the mean ${ }^{107} \mathrm{Ag}$ intensity signal of digested cells in the calibration curve obtained from silver standard solutions and subsequent calculation to the single cell level by taking the counted cell numbers before digestion into account. Thereafter, the obtained $\mathrm{Ag}$ uptake from digested cells reveals a minimal change from 1.4 to $3.4 \mathrm{fg} \mathrm{Ag}$ per cell for THP-1 monocytes incubated at $0.1 \mu \mathrm{g}$ AgNPs $\mathrm{mL}^{-1}$, and from 2.1 to $6.2 \mathrm{fg}$ Ag per cell for cells incubated at $1 \mu \mathrm{g}$ AgNPs $\mathrm{mL}^{-1}$ for 4 and 24 hours, respectively. Moreover, the absolute mass of Ag per single cell was correlated with the number of AgNPs per cell divided by the mass of a single $50 \mathrm{~nm} \operatorname{AgNP}(0.686 \mathrm{fg}$ 
of Ag per AgNP). Table 2 summarizes the number of AgNPs per single cell obtained by SC-ICP-MS analysis and digestion ICP-MS. For comparison of SC-ICP-MS results with the bulk analysis by digestion ICP-MS, a weighted mean (contingency times content) is used since experimentally, a large selection of cells is digested, and the individual distribution is not an issue any longer. Within a standard uncertainty of up to $80 \%$ towards the higher values for the single cell data, which is due to the skewed distribution, the SC-ICP-MS results are confirmed by the "minced-meat" analysis. Therefore, the good agreement between both approaches indicates that the proposed calibration scheme and the SC-ICP-MS method are reliable to study the uptake of AgNPs at the single cell level at low AgNP exposure doses with more detailed information of their distribution among the whole cell population. In contrast, conventional digestion methods in this field assume the same AgNP uptake behaviour for the whole cell population and will lose all information related to individual variability of cells. ${ }^{17,18}$ This promising technique can be applied for quantitative analysis of any metallic inorganic NPs since SC-ICP-MS is able to measure the whole mass spectra without restriction in the mass range. However, SCICP-MS is limited by a single isotope measurement and by the saturation of the detector of the ICP-MS sector field instrument at a low integration time of $0.1 \mathrm{~ms}$ when detecting nearly 100 AgNPs per single cell and thus cannot be applied for those high dose experiments in the counting mode only. This fact is exemplified in Table 2 that presents also the number of AgNPs per single cell obtained by digestion ICP-MS for THP-1 partially differentiated macrophages. According to the ICP-MS digestion results the AgNP uptake at the highest AgNP dose treatment, $1 \mu \mathrm{g} \mathrm{mL}{ }^{-1}$, increased from $116 \pm 2$ to $158 \pm 18$ AgNPs per cell for 4 and 24 hours, respectively. A significant deviation between single cell and digestion results obtained by both approaches was attributed to the saturation of the detector when already detecting nearly $100 \mathrm{AgNPs}$ per cell. The sector field instrument can only measure in the counting mode at the shortest integration time, but the dual mode with automatic switching to analogue mode of the detector allows measurement of all integration times higher than $1 \mathrm{~ms}$.

Moreover, for high AgNP dose experiments resulting in a high number of AgNPs taken up per individual cell, a more accurate validation method providing information on the AgNP uptake distribution inside a cell population should be selected. Mass cytometry, CyTOF, a promising single cell technology based on inductively coupled plasma time of flight mass spectrometry, ICP-TOF-MS, has alternatively been used to study the AgNP uptake by individual THP-1 differentiated macrophage cells and to characterize cells phenotypically in a single measurement (data not shown). Mass cytometry enables the quantitative analysis of AgNPs taken up by THP1 differentiated macrophages and provides additional information on the cell population at it allows the detection of AgNPs associated with nucleated cells by using a metal-tagged DNA intercalator and isotope-tagged antibodies that specifically bind to cellular antigens for cell identification. Moreover, mass cytometry provides information about the fraction of live/dead cells and the fraction of free AgNPs non-associated with intact cells. However, mass cytometry is not able to discriminate between AgNPs externally adsorbed versus AgNPs taken up and these limitations might be circumvented by using the profiling method step FIB/SEM slice and view. ${ }^{\mathbf{1 0}}$ It is noteworthy that the methodology proposed in this study, SCICP-MS, is not able to elucidate the AgNP chemical composition inside the cells as well as a possible transformation by oxidation to ionic Ag. After AgNP uptake, cells might contain a fraction of ionic silver due to AgNP oxidation that would be detected by SC-ICP-MS as a discrete spike signal with an intensity proportional to the total amount of $\mathrm{Ag}$ atoms (from ionic silver or/and AgNPs) contained per individual cell. Such a task might be addressed by using synchrotron-based nanobeam X-ray fluorescence (nano-XRF) microscopy, a promising technique able to visualize $\mathrm{Ag}^{+}$in living cells after AgNP internalization. ${ }^{19}$

Table 2 Quantitative analysis of AgNPs in single cells by SC-ICP-MS and digestion ICP-MS. Mean values and standard deviations correspond to two biological experiments measured in two replicates for THP-1 monocytes and one biological experiment measured in two replicates for THP1 partially differentiated macrophages

\begin{tabular}{|c|c|c|c|c|c|}
\hline \multirow[b]{3}{*}{$\begin{array}{l}\text { Exposure } \\
\text { time (h) }\end{array}$} & \multirow[b]{3}{*}{$\begin{array}{l}\text { Exposure dose } \\
\left(\mu \mathrm{g} \mathrm{Ag} \mathrm{mL}^{-1}\right)\end{array}$} & \multicolumn{2}{|c|}{ THP-1 monocytes } & \multicolumn{2}{|c|}{$\begin{array}{l}\text { THP-1 partially differentiated } \\
\text { macrophages }\end{array}$} \\
\hline & & SC-ICP-MS & $\begin{array}{l}\text { Digestion } \\
\text { ICP-MS }\end{array}$ & SC-ICP-MS & $\begin{array}{l}\text { Digestion } \\
\text { ICP-MS }\end{array}$ \\
\hline & & $\begin{array}{l}\text { Mean, AgNP } \\
\text { per cell }\end{array}$ & $\begin{array}{l}\text { Mean, AgNP } \\
\text { per cell }\end{array}$ & $\begin{array}{l}\text { Mean, AgNP } \\
\text { per cell }\end{array}$ & $\begin{array}{l}\text { Mean, AgNP } \\
\text { per cell }\end{array}$ \\
\hline 4 & - & 0 & 0 & 0 & 0 \\
\hline \multicolumn{6}{|l|}{24} \\
\hline 4 & 0.1 & 1 & $2 \pm 1$ & 9.38 & $16 \pm 1$ \\
\hline 24 & & 1 & $4 \pm 2$ & 4.22 & $7 \pm 1$ \\
\hline 4 & 1 & 3 & $3 \pm 2$ & 46.77 & $116 \pm 2$ \\
\hline 24 & & 7 & $9 \pm 2$ & 45.07 & $158 \pm 18$ \\
\hline
\end{tabular}




\section{Conclusions}

The ability of SC-ICP-MS to study the uptake of AgNPs by THP-1 monocytes and their partially differentiated macrophages at the single cell level after exposure at low AgNP doses are demonstrated here for the first time. The results obtained for SC-ICPMS analysis were also compared with digestion ICP-MS highlighting that SC-ICP-MS could be a new promising tool to track, assess and understand the uptake of AgNPs by individual cells. As has been shown in this study, not all cells respond alike since some individual cells were able to take up more than one single AgNP while some individual cells did not take up any AgNPs at all. We have seen for the first time that some cells can have a significantly higher uptake rate compared to a mean value, and so even in low dose experiments a high number of NPs in cells are detected, a finding which is of significant toxicological relevance. Those individual cells which did not take up any AgNPs at all (roughly 6-7\% of AgNP events detected by CyTOF were not associated with cells) are not visible in the single cell experiment presented, but have been investigated also using a mass cytometry approach in a separate study (data not shown). ${ }^{18}$

Under the optimized conditions, SC-ICP-MS has important advantages as it requires minimal sample preparation, is fast, selective and very sensitive, and provides immediate information on the NP content of individual cells and on the related variance in a population of cells. LODs in the sub-fg region at the single cell level are achieved by using this promising analytical tool, opening further applications to monitor the uptake by individual cells of any metallic NPs. Additionally, the ions released to the supernatant from NPs are detectable along with the particle form by using this methodology. However, simultaneous multi-elemental detection is not possible by SCICP-MS and for this purpose mass cytometry has been used in a parallel study to get more insights into cell phenotyping and AgNP bio-distribution measured under high throughput conditions with detection of many thousand cells per second. Nevertheless, this SC-ICP-MS approach presents huge potential over the most conventional lysate-based assays overcoming some of their limitations and is a new promising technology to study NP-cell interactions in the field of biomedicine and nanotoxicology.

\section{Conflicts of interest}

There are no conflicts to declare.

\section{Acknowledgements}

One of the authors (Ana Lopez-Serrano Oliver) acknowledges funding by the Marie Curie Actions, Horizon 2020. Norbert Jakubowski acknowledges financial support for this project by the Federal Institute for Risk Assessment (BfR). The work of authors from BAM is financially supported by the Federal Ministry of Economy and Energy. This work was supported by the Leibniz Science Campus Chronic Inflammation (www.chronische-entzuendung.org). Sabine Baumgart is funded by the German Federal Ministry of Education and Research (BMBF) within the framework of the: "Med research and funding concept (sysINFLAME, grant \# 01ZX1306B)".

\section{Notes and references}

1 K. Kleparnik and F. Foret, Anal. Chim. Acta, 2013, 800, 12.

2 E. J. Lanni, S. S. Rubakhin and J. V. Sweedler, J. Proteomics, 2012, 75, 5036-5051.

3 R. Trouillon, M. K. Passarelli, J. Wang, M. E. Kurczy and A. G. Ewing, Anal. Chem., 2013, 85, 522-542.

4 A. Ivask, A. J. Mitchell, A. Malysheva, N. H. Voelcker and E. Lombi, Wiley Interdiscip. Rev.: Nanomed. Nanobiotechnol., 2017, e1486, DOI: 10.1002/wnan.1486.

5 G. Cerchiaro, T. M. Manieri and F. R. Bertuchi, Metallomics, 2013, 5, 1336-1345.

6 M. Milic, G. Leitinger, I. Pavicic, M. Z. Avdicevic, S. Dobrovic, W. Goessler and I. V. Vrcek, J. Appl. Toxicol., 2014, 35(6), 581592.

7 K. S. Ho and W. T. Chan, J. Anal. At. Spectrom., 2010, 25, 1114-1122.

8 I.-L. Hsiao, F. S. Bierkandt, P. Reichardt, A. Luch, Y.-J. Huang, N. Jakubowski, J. Tentschert and A. Haase, J. Nanobiotechnol., 2016, 14, 50.

9 O. Lunov, T. Syrovets, C. Loos, J. Beil, M. Delacher, K. Tron, G. U. Nienhaus, A. Musyanovych, V. Mailaender, K. Landfester and T. Simmet, ACS Nano, 2011, 5(3), 16571669.

10 E. Guehrs, M. Schneider, C. M. Günther, P. Hessing, K. Heitz, D. Wittke, A. López-Serrano, N. Jakubowski, J. Plendl, S. Eisebitt and A. Haase, J. Nanobiotechnol., 2017, 15, 21.

11 K. Shigeta, G. Koellensperger, E. Rampler, H. Traub, L. Rottmann, U. Panne, A. Okino and N. Jakubowski, J. Anal. At. Spectrom., 2013, 28, 637-645.

12 B. R. Schmidt, S. A. Pergantis, D. Esteban-Fernández, N. Jakubowski and D. Günther, Anal. Chem., 2015, 87(17), 8687-8694.

13 K. Kanaki and S. A. Pergantis, J. Anal. At. Spectrom., 2016, 31, 1041-1046.

14 L. N. Zheng, M. Wang, B. Wang, H. Q. Chen, H. Ouyang, Y. L. Zhao, Z. F. Chai and W. Y. Feng, Talanta, 2013, 116, 782-787.

15 S. Meyer, A. Lopez-Serrano, H. Mitze, N. Jakubowski and T. Schwertle, Metallomics, 2018, 10, 73-76.

16 L. Mueller, A. J. Herrmann, S. Techritz, U. Panne and N. Jakubowski, Anal. Bioanal. Chem., 2017, 409, 3667-3676.

17 W. Liu, Y. Wu, C. Wang, H. C. Li, T. Wang, C. Y. Liao, L. Cui, Q. F. Zhou and B. Yan, Nanotoxicology, 2010, 4, 319-330.

18 C. Greulich, J. Diendorf, T. Simon, G. Eggeler, M. Epple and M. Koller, Acta Biomater., 2011, 7(1), 347-353.

19 G. Veronesi, A. Deniaud, T. Gallon, P.-H. Jouneau, J. Villanova, P. Delangle, M. Carrière, I. Kieffer, P. Charbonnier, E. Mintz and I. Michaud-Soret, Nanoscale, 2016, 8, 17012-17021. 